\title{
Analysis on Dynamic Transmission Accuracy for RV Reducer
}

\author{
Fengshou Zhang ${ }^{1}$, Pengfei $\mathrm{Li}^{2,}$, , Peng Zhu², Xingxing Yang ${ }^{2}$ and Wenhe Jiang ${ }^{3}$ \\ ${ }^{1}$ School of Medical Technology and Engineering, Henan University of Science and Technology, Luoyang, China \\ ${ }^{2}$ School of Mechatronics Engineering, Henan University of Science and Technology, Luoyang, China \\ ${ }^{3}$ School of Mechatronics Engineering, China University of Mining and Technology, Xuzhou, China \\ Corresponding Email:18238832971@163.com
}

\begin{abstract}
By taking rotate vector (RV) reducer as the research object, the factors affecting the transmission accuracy are studied, including the machining errors of the main parts, assembly errors, clearance, micro-displacement, gear mesh stiffness and damping, bearing stiffness. Based on Newton second law, the transmission error mathematical model of RV reducer is set up. Then, the RV reducer transmission error curve is achieved by solving the mathematical model using the Runge-Kutta methods under the combined action of various error factors. Through the analysis of RV reducer transmission test, it can be found that there are similar variation trend and frequency components compared the theoretical research and experimental result. The presented method is useful to the research on dynamic transmission accuracy of RV reducer, and also applies to research the transmission accuracy of other cycloid drive systems.
\end{abstract}

\section{Introduction}

Rotate vector (RV) reducer is a high-performance precision transmission system, developed from the cycloidal pinwheel transmission. Currently, the research of high-performance precision transmission component and system is one of the key technologies of the mechanical engineering science, the analysis of RV reducer transmission precision has become an important research topic. To get higher transmission precision of RV reducer, the transmission error should be strictly controlled.

Domestic and foreign scholars have done lots of in-depth researches on the precision of general gear transmission, while the study of transmission accuracy for cycloidal-pin wheel mechanism and RV reducer is insufficient. In foreign countries, the United States Hughes companies Blanche and the Japanese Professor Teruaki Hidaka had studied it [1-3]. In China, the research on driving accuracy of cycloid system started relatively late and mostly confined geometry or static methods [4-7]. To improve the accuracy and stability of system output, it is necessary to analyse and research the dynamic transmission error on RV reducer, thus to reveal its dynamic behaviors influence on transmission precision in nature. This paper applies the method of nonlinear to study the transmission accuracy of RV reducer.

\section{The transmission error mathematical model of RV reducer}

\subsection{System equivalent model}

The structure of RV reducer is complex and the parts are more. Based on lumped mass method and dynamic substructure method, the equivalent model of RV reducer is established. The lumped mass method is also called massspring method, that is to say, the parts of large mass, big inertia and small elasticity can be regarded as the mass concentration of particles and rigid bodies, and the parts of little mass, high elasticity and large damping can be regarded as elastic elements or damping elements, their mass can be neglected or equivalent to the concentrated mass, rigid bodies are coupled by elastic elements or damping elements, the spring forces and damping forces are rigid body inter-atomic forces. The dynamic substructure method is to decompose the complex structure into some simple substructures, and then analyse the model of each substructure, according to the relationship between the each substructure, the analysis models of substructure are integrated into the analysis model of the whole structure, the whole process that is the analysis process of the whole to the local and then to the whole.

The RV-40E reducer is mainly composed of a sun gear, two planetary gears, two crank shafts, two cycloids, pin gears, planetary frame and the pin wheel housing. The equivalent model [2] is shown in Figure1. Taking the fixed pin gear distribution circle center as the origin to establish static coordinate system $(\mathrm{X}, \mathrm{Y})$, regarding the $J$-th cycloid 
centroid $O_{j}$ as origin and the eccentric direction of cycloid as $\eta_{j}$ direction to establish the dynamic coordinate $\operatorname{system}\left(\eta_{j}, \xi_{j}\right), \Phi_{i}$ are the relative position of the planetary gears $(i=1,2, i$ is the number of planetary gears $), \Psi_{j}$ are the relative position of cycloid centroids $(j=1,2, j$ is the number of cycloids).

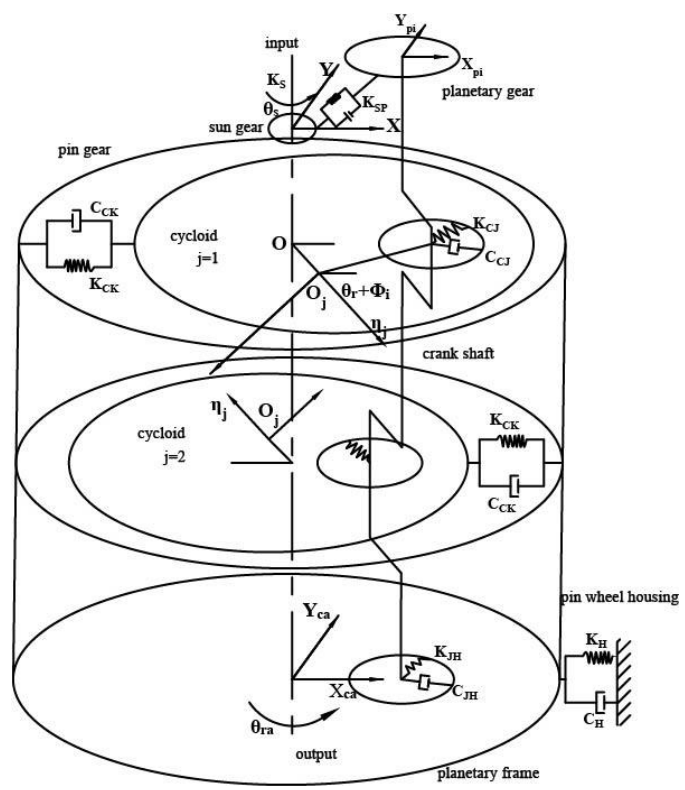

Fig. 1. Dynamic equivalent model of RV reducer.

In the equivalent model, the main parts of reducer are replaced by lumped mass, the bearing stiffness, and the gear meshing stiffness and damping are replaced by the spring element and damping element, such as, KS is the supporting stiffness of gear shaft, The sun gear and planetary gear meshing stiffness is KSP, CSP is the meshing damping, KCJ is the bearing stiffness between the crank shaft cam and cycloid shaft hole, $\mathrm{KJH}$ is the bearing stiffness between the crank shaft and planet carrier shaft hole, KH is the bearing stiffness between the planet carrier and pin gear housing, The cycloid and pin gear meshing stiffness is KCK, CCK is the meshing damping, The stiffness and damping values are calculated by using the related formulas.

When a small torque acts on the output shaft of reducer, because of machining errors, assembly errors, clearances and deformations, the parts' centroid positionand angle will deviation from the theoretical position, the tiny linear displacement and angular displacement are referred to as micro displacement. Reflected in the equivalent model. Xs, Ys are micro displacement of the center gear, Xpi, Ypi and $\theta$ pi- $\theta p$ (the planetary gear and the crank shaft are regarded as an integral whole) are micro displacement of the planetary gear and crank shaft, $\eta \mathrm{sj}, \theta j-\theta \mathrm{r}$ and $\theta \mathrm{oj}-\theta \mathrm{p}$ are micro displacement of the cycloid, $\mathrm{Xc}, \mathrm{Yc}$ and $\theta \mathrm{ra}-\theta \mathrm{r}$ are micro displacement of the planet carrier. $\theta \mathrm{s}$ is the theoretical angle of sun gear, $\theta \mathrm{p}$ is the theoretical rotation angle of planetary gear, $\theta \mathrm{pi}$ is the actual rotation angle of planetary gear, $\theta \mathrm{r}$ is the theoretical angle of planetary carrier, $\theta \mathrm{ra}$ is the actual angle of planetary carrier, $\theta \mathrm{j}$ is the actual rotation angle of cycloid, $\theta \mathrm{oj}$ is the revolution angle of cycloid .

\subsection{Description of the various errors of parts}

When analyzing the impact of error factors on RV reducer transmission accuracy, the following error factors are considered: the machining eccentric error of sun gear is $\left(E_{s}, \beta_{s}\right), E_{s}$ is the size of error, $\beta_{s}$ is the direction of error. Other eccentric or assembly error representation methods are similar to this. The assembly error of sun gear is $\left(E_{s a}, \beta_{s a}\right)$, the machining eccentric error of Planetary gear is $\left(E_{p i}, \beta_{p i}\right)$, the eccentric error of crank shaft eccentric cam is $\left(E_{d j i}, \beta_{d j i}\right)$, the eccentric error of planet carrier crank shaft hole is $\left(E_{c j i}, \beta_{c j i}\right)$, the eccentric error of crank shaft hole is $\left(E_{h i}, \beta_{h i}\right)$, the assembly error of planet carrier is $\left(E_{c}, \beta_{c}\right)$, the profile deviation of pin gear is $E_{R k}$, the tooth pitch accumulated error is $E_{A R k}$, the profile deviation of cycloid is $P_{j k}$, the tooth pitch accumulated error is $A P_{j k}$, the amount of equidistant modification is $\Delta r_{r p}$, the amount of moved distance modification is $\Delta r_{p}, \delta_{c j}$ is the bearing clearance at cycloid crank shaft hole, $\delta_{j h}$ is the bearing clearance at planet carrier crank shaft hole, $\delta_{h}$ is the bearing clearance between planet carrier and pin gear housing, $e_{k}$ is the sum of pin wheel radius error and pin gear arc-groove radius error.

\subsection{The mathematical model of $\mathrm{RV}$ reducer dynamic transmission accuracy}

In the equivalent model, the spring force and damper force are the interaction force between the parts, that are the product of spring stiffness coefficient and the equivalent error, the product of damping coefficient and the equivalent 
error first derivative, namely $F=K \delta$ and $P=C \dot{\delta}$. Analyzing the force of the main parts in the ideal position, based on the newton second law, the mathematical model of dynamic transmission accuracy is established.

\subsubsection{The dynamic equation of center gear}

$$
\left\{\begin{array}{l}
m_{s} \ddot{X}_{s}+F_{S X}+\sum_{i=1}^{2}\left(F_{S P i}+P_{S P i}\right) \sin \left(\theta_{r}+\phi_{i}-\alpha\right)=0 \\
m_{s} \ddot{Y}_{s}+F_{S Y}-\sum_{i=1}^{2}\left(F_{S P i}+P_{S P i}\right) \cos \left(\theta_{r}+\phi_{i}-\alpha\right)=0 \\
J_{s} \ddot{\theta}_{s}+R_{s} \sum_{i=1}^{2}\left(F_{S P i}+P_{S P i}\right)-T_{0}=0
\end{array}\right.
$$

Where, $m_{s}$ is the mass of center gear, $J_{s}$ is the moment of center gear, $R_{s}$ is the radius of base circle of center gear, T0 is the input shaft torque.

\subsubsection{The dynamic equation of planet carrier}

$$
\left\{\begin{array}{l}
m_{c} \ddot{X}_{c}+\sum_{i=1}^{2} F_{J H X}-F_{H X}=0 \\
m_{c} \ddot{Y}_{c}+\sum_{i=1}^{2} F_{J H Y}-F_{H Y}=0 \\
J_{c} \ddot{\theta}_{r}+R_{s p} \sum_{i=1}^{2} F_{J H X} \sin \left(\theta_{r}+\phi_{i}\right)-R_{s p} \sum_{i=1}^{2} F_{J H Y} \cos \left(\theta_{r}+\phi_{i}\right)+T=0
\end{array}\right.
$$
torque.

Where, $\mathrm{mc}$ is the mass of the planet carrier, Jc is the moment of inertia of the planet carrier, $\mathrm{T}$ is the output shaft

\subsubsection{The dynamic equation of planetary gear (include the crank shaft)}

$$
\left\{\begin{array}{l}
m_{c p}\left[\ddot{X}_{p i}-R_{s p} w_{r}^{2} \cos \left(\theta_{r}+\phi_{i}\right)-R_{s p} \ddot{\theta}_{r a} \sin \left(\theta_{r}+\phi_{i}\right)\right]-\left(F_{S P i}+P_{S P i}\right) \sin \left(\theta_{r}+\phi_{i}-\alpha\right)+\sum_{j=1}^{2} F_{C J X}+F_{J H X}=0 \\
m_{c p}\left[\ddot{Y}_{p i}-R_{s p} w_{r}^{2} \sin \left(\theta_{r}+\phi_{i}\right)+R_{s p} \ddot{\theta}_{r a} \cos \left(\theta_{r}+\phi_{i}\right)\right]+\left(F_{S P i}+P_{S P i}\right) \cos \left(\theta_{r}+\phi_{i}-\alpha\right)+\sum_{j=1}^{2} F_{C J Y}+F_{J H Y}=0 \\
J_{c p} \ddot{\theta}_{p i}+R_{p}\left(F_{S P i}+P_{S P i}\right)-e \sum_{j=1}^{2} F_{C J X} \sin \left(\theta_{p}+\psi_{j}\right)-e \sum_{j=1}^{2} F_{C J Y} \cos \left(\theta_{p}+\psi_{j}\right)=0
\end{array}\right.
$$

Where, $m_{c p}$ is the sum of planetary gear mass and crank shaft mass, $J_{c p}$ is the moment of inertia of planetary gear and crank shaft, $w_{r}$ is the theoretical angular velocity of planet carrier, Rsp is the center distance of center gear and planetary gear.

\subsubsection{The dynamic equation of cycloid}

$\left\{\begin{array}{l}m_{b}\left[\ddot{\eta}_{j s} \cos \left(\theta_{p}+\psi_{j}\right)-e w_{p}^{2} \cos \left(\theta_{p}+\psi_{j}\right)-e \ddot{\theta}_{o j} \sin \left(\theta_{p}+\psi_{j}\right)\right]-\sum_{i=1}^{2} F_{C J X}-\sum_{k=m}^{n}\left(F_{C K}+P_{C K}\right) \cos \left(\alpha_{j k}+\theta_{p}+\psi_{j}\right)=0 \\ m_{b}\left[-\ddot{\eta}_{j s} \sin \left(\theta_{p}+\psi_{j}\right)+e w_{p}^{2} \sin \left(\theta_{p}+\psi_{j}\right)-e \ddot{\theta}_{o j} \cos \left(\theta_{p}+\psi_{j}\right)\right]+\sum_{i=1}^{2} F_{C J Y}+\sum_{k=m}^{n}\left(F_{C K}+P_{C K}\right) \sin \left(\alpha_{j k}+\theta_{p}+\psi_{j}\right)=0 \\ \mathrm{~J}_{o} \ddot{\theta}_{j}-R_{d} \sum_{k=m}^{n}\left(F_{C K}+P_{C K}\right) \sin \alpha_{j k}+R_{o h} \sum_{i=1}^{2} F_{C J X} \sin \left(\theta_{r}+\phi_{i}\right)-R_{o h} \sum_{i=1}^{2} F_{C J Y} \cos \left(\theta_{\mathrm{r}}+\phi_{i}\right)=0\end{array}\right.$

Where, $\mathrm{mb}$ is the mass of cycloid, $\mathrm{J} 0$ is the moment of cycloid, wp is the theoretical rotation angular velocity of the planetary gear.

The dynamic equations can be converted into the general matrix form:

$$
M \ddot{X}+C \dot{X}+K X=F
$$


Where, $\mathbf{X}$ is the displacement vector of equivalent model, $\mathbf{X}^{\mathbf{T}}=\left[\mathrm{X}_{\mathrm{s}}, \mathrm{Y}_{\mathrm{s}}, \theta_{\mathrm{s}}, \mathrm{X}_{\mathrm{p} 1}, \mathrm{Y}_{\mathrm{p} 1}, \theta_{\mathrm{p} 1}, X_{\mathrm{p} 2}, Y_{\mathrm{p} 2}, \theta_{\mathrm{p} 2}, \eta_{\mathrm{s} 1}, \theta_{1}, \theta_{\mathrm{o} 1}, \eta_{\mathrm{s} 2}, \theta_{2}, \theta_{\mathrm{o} 2}, X_{\mathrm{c}}, Y_{\mathrm{c}}, \theta_{\mathrm{ra}}\right], \mathbf{M}$ is the mass matrix, $\mathbf{K}$ is the stiffness matrix, $\mathbf{C}$ is the damp matrix, $\mathbf{F}$ is the force vector.

By solving the differential equations, the actual angle of the output shaft can be obtained, if the transmission ratio is $i$, the transmission error is $\Delta \theta_{r a}=\theta_{r a}-\theta_{s} / i$.

\section{Solving the equations and experimental confirmation}

Taking the RV-40E reducer as the research object, the transmission error dynamic model of RV reducer is established. The solid part models of RV reducer are built, the quality and the moment of inertia of each part is solved. The damping and stiffness of involute planetary gear is calculated by using the theory of elasticity, iterativing the meshing damping and stiffness between cycloid gear which has been modified and the pin gear by using the computer programming, the equivalent stiffness of the bearings are calculated by Hertz formula. The basic parameters and correlated errors are shown in Table 1 to Table 4 . the errors' unit is $\left(\mu \mathrm{m},{ }^{\circ}\right)$, due to the errors of sun gear and planetary gear have little impact on the transmission accuracy, thus can be neglected [3].

Table 1.The basic structure parameters of RV-40E reducer.

\begin{tabular}{|c|c|c|c|}
\hline \multicolumn{2}{|c|}{ Planetary gear drive } & \multicolumn{2}{c|}{ Cycloidal pin-gear drive } \\
\hline $\begin{array}{c}\text { sun gear tooth } \\
\text { number }\end{array}$ & 12 & $\begin{array}{c}\text { Cycloid tooth } \\
\text { number }\end{array}$ & 39 \\
\hline $\begin{array}{c}\text { planetary gear } \\
\text { tooth number }\end{array}$ & 36 & $\begin{array}{c}\text { pin gear tooth } \\
\text { number }\end{array}$ & 40 \\
\hline modulus & 1.5 & $\begin{array}{c}\text { the radius of } \\
\text { pinwheel } \\
\text { distribution } \\
\text { circle/mm }\end{array}$ & 64.0 \\
\hline $\begin{array}{c}\text { meshing } \\
\text { pressure angle }\end{array}$ & 20 & $\begin{array}{c}\text { pin wheel } \\
\text { radius/mm }\end{array}$ & 3 \\
\hline $\begin{array}{c}\text { transmission } \\
\text { ratio }\end{array}$ & 121 & Eccentricity/mm & 1.3 \\
\hline
\end{tabular}

Table 2. The manufacturing error between the crank shaft and cycloid.

\begin{tabular}{|c|c|c|c|c|}
\hline \multirow{2}{*}{$\begin{array}{c}\text { error } \\
\text { location }\end{array}$} & \multicolumn{2}{|c|}{$\begin{array}{c}\text { crank shaft cam } \\
\text { eccentric error }\end{array}$} & \multicolumn{2}{c|}{$\begin{array}{c}\text { cycloid crank shaft } \\
\text { hole eccentric error }\end{array}$} \\
\cline { 2 - 5 } & $\begin{array}{c}\text { crank } \\
\text { shaft 1 }\end{array}$ & $\begin{array}{c}\text { crank } \\
\text { shaft 2 }\end{array}$ & $\begin{array}{c}\text { crank } \\
\text { shaft 1 }\end{array}$ & $\begin{array}{c}\text { crank } \\
\text { shaft 2 }\end{array}$ \\
\hline $\begin{array}{c}\text { cycloid } \\
1\end{array}$ & $(3.5,30)$ & $(3,195)$ & $(3.5,40)$ & $\begin{array}{c}3.5,215 \\
)\end{array}$ \\
\hline $\begin{array}{c}\text { cycloid } \\
2\end{array}$ & $\left(4,140^{\circ}\right)$ & $(4.5,85)$ & $(3,130)$. & $(3,130)$ \\
\hline
\end{tabular}

Table 3. Planetary carrier crank shaft hole eccentric error and assembling error.

\begin{tabular}{|c|c|c|}
\hline \multicolumn{2}{|c|}{$\begin{array}{l}\text { planetary carrier crank } \\
\text { shaft hole eccentric error }\end{array}$} & $\begin{array}{l}\text { planetary carrier } \\
\text { assembling error }\end{array}$ \\
\hline $\begin{array}{c}\text { crank shaft } \\
1\end{array}$ & $\begin{array}{c}\text { crank shaft } \\
2\end{array}$ & \multirow{2}{*}{$(4,30)$} \\
\hline$(3.5,195)$ & $(3,75)$ & \\
\hline
\end{tabular}

Table 4. The correlated errors of cycloid gear and pin gear.

\begin{tabular}{|c|c|c|}
\hline error types & cycloid & pin gear \\
\hline profile error & 8 & 5 \\
\hline $\begin{array}{c}\text { total cumulative pitch } \\
\text { error }\end{array}$ & 6 & 8 \\
\hline
\end{tabular}

The basic parameters and correlated errors are substituted into dynamic equations, and the equations are solved by using the Runge-Kutta method, the actual transmission error is measured by means of test platform. The numerical simulation and experimental result are respectively shown in Figure2 and Figure3. 


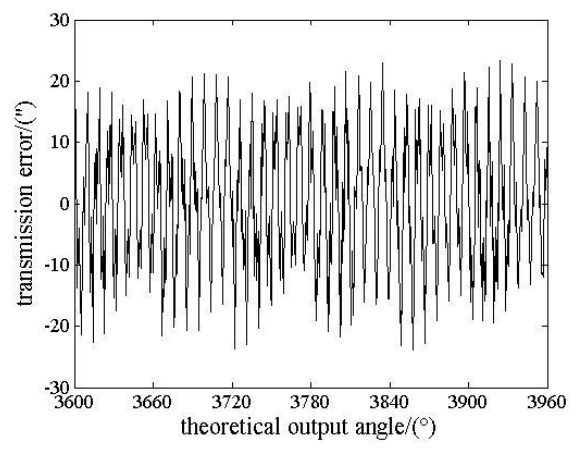

(a) The theoretical transmission error curve.

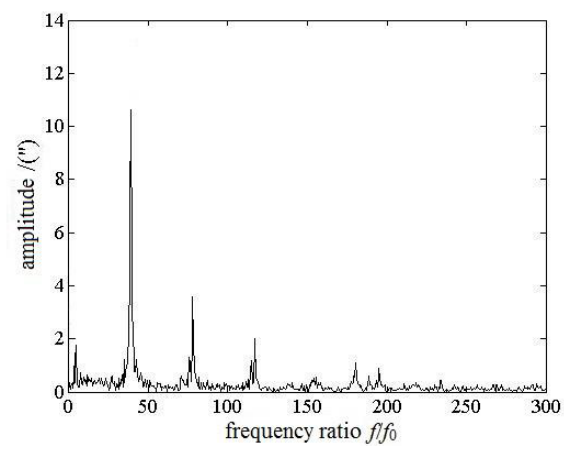

(b) The spectrum characteristic

Fig. 2. The theoretical results of RV reducer transmission error.

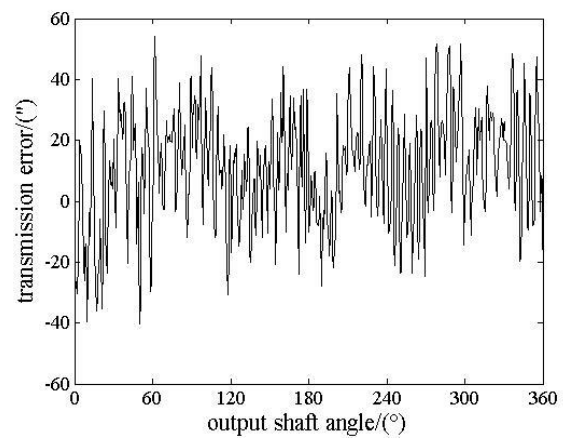

(a) The experimental transmission error curve

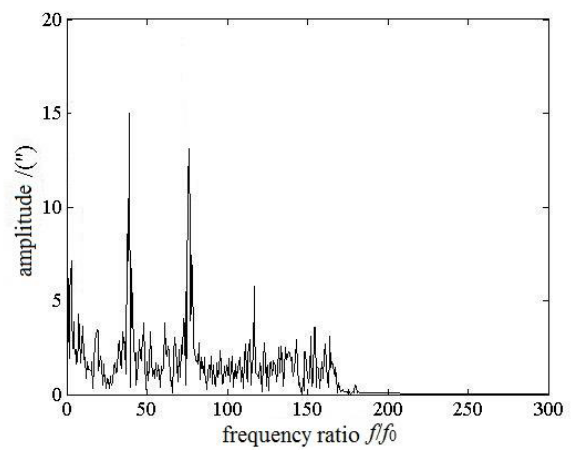

(b) The spectrum characteristic

Fig. 3. The experimental results of RV reducer transmission error. 
To explore the spectral characteristics of RV reducer transmission error, the spectrum can be obtained by Fourier transform, as shown in Fig 2(b) and Fig 3(b), $f$ is the frequency of output error, $f_{0}$ is the frequency of output shaft rotation, The frequency ratio $f / f_{0}$ is the number of output error changes per revolution. As shown in Fig 2 and Fig 3 , the theoretical result and experimental result have similar trend and frequency components, Therefore, the mathematical model established in this paper can correctly reveal the variation of RV reducer transmission error.

In addition, by simulating the different error parameters and comparing the effection of each error factor on the accuracy of RV reducer. It can be obtained that the correlated errors of the involute gear in one-stage gearing have little influence on the transmission accuracy of RV reducer. In the two stage of the transmission part, crank shaft cam eccentric error, cycloid crank shaft hole eccentric error, cycloid profile error and total cumulative pitch error, pin gear profile error and total cumulative pitch error have a great influence on transmission accuracy, which depend on the error size, the action direction and the combination mode. So the error factors in secondary transmission part should be taken seriously when a RV reducer is designed and produced, by controlling the greater impact factors, the transmission accuracy can be effectively improved.

\section{Conclusion}

In comprehensive consideration of the main parts machining errors, assembly errors, clearance, micro-displacement, gear meshing stiffness and damping, bearing stiffness, the dynamic transmission accuracy mathematical model of RV reducer is established according to Newton second law and is solved by using Runge-Kutta methods. The theoretical research and test analysis show that the results of numerical simulation agree with that of experiment. The method provides a theoretical basis for further research and improvement of cycloid pin gear transmission system.

\section{Acknowledgement}

Research is supported by Scientific and Technological Project of Henan Province (162102210049).

\section{References}

1. Yang D. C. H \& Blanche J. G. Design and application guidelines for cycloid drives with machining tolerances. Mechanism and Machinery Theory, 25(5), pp. 487-501,( 1990).

2. Teruaki Hidaka, Takeshi Ishida \& Hongyou Wang. Rotational transmission error of K-H-V-type planetary gear with cycloid gears (1st Report, Analytical Method of the Rotational Transmission Error). Japan Society of Mechanical Engineers. 60(570), pp. 645-653, (1994).

3. Teruaki Hidaka, Takeshi Ishida \& Hongyou Wang. Rotational transmission error of K-H-V-type planetary gear with cycloid gears (2nd Report, Effects of Manufacturing and Assembly Errors on Rotational Transmission Error). Japan Society of Mechanical Engineers. 60(578), pp. 3510-3517, (1994).

4. Han Lin-Shan, Wu Lan-Ying \& Shen Yun-Wen. Sensitivity analysis of the $2 \mathrm{~K}-\mathrm{V}$ reducer transmission precision. Mechanical Science and Technology, 25(10), pp. 1366-1369,(2010).

5. Yang $\mathrm{Yu}-\mathrm{Hu}$, Zhang Jie $\mathrm{Xu} \mathrm{Li-Xin.} \mathrm{The} \mathrm{transmission} \mathrm{accuracy} \mathrm{analysis} \mathrm{of} \mathrm{RV} \mathrm{reducer.} \mathrm{Journal} \mathrm{of} \mathrm{Tianjin}$ University, 46(7), pp. 623-628, (2013).

6. Zhu Bin, Qin Wei, Liu Jing, et al. Simulation and Analysis of Dynamical Transmission Precision of 2K-V Cycloid Pin Gear Reducer Based on Multi-body System Dynamics. Advanced Materials Research: Advanced Design Technology,3(08): 2205-2210.(2012).

7. Zhang Jin, Sun YongGuo. Backlash Analysis of RV Reducer Based on Error Factor Sensitivity and Monte-carlo Simulation. Science and Engineering Research Support Society, 7(2): 283-291,(2014). 